Discussion Paper No. 804

\title{
PREVENTION OF COMPETITION BY COMPETITION LAW: EVIDENCE FROM UNBUNDLING REGULATION ON FIBER-OPTIC NETWORKS IN JAPAN
}

Naoaki Minamihashi

The $13^{\text {th }}$ ISER-Moriguchi Prize (2010)

Awarded Paper

March 2011

The Institute of Social and Economic Research

Osaka University

6-1 Mihogaoka, Ibaraki, Osaka 567-0047, Japan 


\title{
Prevention of Competition by Competition Law: Evidence from Unbundling Regulation on Fiber-Optic Networks in Japan*
}

\author{
Naoaki Minamihashi ${ }^{\dagger}$ \\ Boston University
}

This Draft: Feb, 2011

First Draft: July, 2010

\begin{abstract}
This paper finds that a regulation that promotes competition in one market may decrease competition in other related markets. Policy makers in the telecommunication industry currently are facing an important decision about whether to continue unbundling regulations on new optical-fiber lines. I find that unbundling regulation prevents new providers from building optical-fiber networks, by estimating a dynamic entry game with a dataset of fiber-optic network constructions in Japan from 2005 to 2009. In particular, when a new technology is introduced, unbundling regulation has an oligopolization effect on the regulated firms. This finding in the Japanese telecommunications industry suggests that unbundling regulation during periods of new technology diffusion may reduce the price of service but also decrease competition in the infrastructure market. (JEL K21, L43, L96 Keywords: Unbundling, FTTH, Entry and Exit, Dynamic Game, Fiber-optic Networks)
\end{abstract}

*This paper has benefitted from the continuous advice, encouragement, and overall guidance of Marc Rysman. I am indebted to Takanori Ida, Jordi Jaumandreu, Joshua Lustig, Masatsugu Tsuji, and Ingo Vogelsang for discussions that generated great improvements. I also thank to Charles Ho, Chun-Yu Ho, Toshifumi Kuroda, Mitsuru Sunada, Elif Nilay Yilmaz and participants in International Telecommunications Society, Japan Economic Association, Japan Fair Trade Committee and Osaka university. I acknowledge Hiroshi Ohashi, Ministry of International Affairs and Communication and NTT East for data usage. This paper was awarded the 13th Moriguchi Prize by the ISER at Osaka University, and I acknowledge suggestions from annoymous referees. The author takes full responsibility for any remaining errors.

†Boston University, 270 Baystate Road, Boston, MA, 02215, US Mail: naoaki@bu.edu Web: http://people.bu.edu/naoaki/ 
Should we protect competition with competition law? Historically, government authorities have engaged in fostering competition in industries with antitrust laws. They have banned abusive conduct, such as tying or predatory pricing, and have prevented large mergers and acquisitions. However, in recent developments of globalization, technological progress, and the de facto standard economy, we can observe oligopolistic structures in some markets. ${ }^{1}$ The authorities are deregulating or reinterpreting competition law and regulations to keep up with the current society's needs.

Telecommunications is one of the industries where competition is highly protected by regulations. Governments around the world adopt a regulation called a Local-Loop Unbundling (LLU) to accelerate competition. The law requires that telephone companies that have monopolistic local premises (called "local loops") should share their lines with other companies at a low price. This is because the telecommunications industry is characterized by a "natural monopoly" due to its huge, sunk, up-front and fixed costs, and there is no competition in the market without the regulation. If governments regulate carriers with facilities to allow other firms to use their premises, then firms with no facilities can easily enter the market, and consumers can obtain a wide variety of high quality services at a low cost as a result of the competition. Industries that have natural monopoly characteristics, such as electric, gas, and railroad industries, also have similar unbundling regulations.

Policy makers in telecommunications, however, are confronted with a new problem in the diffusion process of building fiber-optic networks, called FTTH (fiber to the home). The unbundling regulation decreases the incentive for firms to invest in the latest technology; few firms build home fiber-optic networks. This is because they cannot get monopolistic profits if they have to lend the fiber lines at a regulated low cost. Compared to the traditional metal line, this fiber-optic line can transfer large amounts of data with faster transfer rates, enabling services such as high speed internet, high qual-

\footnotetext{
${ }^{1}$ For example: airlines, OS software, digital music downloads, credit cards, search engines, etc.
} 
ity digital voice, HDTV programs and cloud computing. Therefore, the regulation of fiber-optic networks is one of the most important concerns of policymakers in the world today. A change in unbundling regulation would have immense effects on investments, penetration of fiber-optic networks, consumer welfare, and, ultimately, a country's productivity. For example, in 2003, the United States' Federal Communication Commission (FCC) amended the law and removed unbundling regulations on fiber-optic premises in order to accelerate building competition among carriers and promote investments in fiber networks, even though many companies without facilities objected. ${ }^{2}$

However, in relation to unbundling regulation's importance, the literature that studies it is limited. This is because the municipal level data set is rarely available and building of the new networks, such as fiber-optic networks, is uncommon. For example, in the telecommunication industry, metal networks were built more than 50 years ago; the new networks that are going to be formed will be the first since the 1960s. Furthermore, home fiber-optic networks have not yet been installed in most countries. Japan, however, in 2005-2009 experienced a rapid increase of fiber-optic networks (FTTH) under the unbundling regulation on fiber premises. There, authorities and regulated firms also offered micro-level data. Tables 1 and 2 show the international comparisons for the diffusion and regulation of fiber networks. We can observe that Japan is one of the rare countries that experienced penetration and continued unbundling regulation.

Previous literature mainly studies the effects of unbundling on service markets. Greenstein and Mazzeo (2006) found that unbundling widened the variety of services, and Economides, Seim and Viard (2008) found that competition in service markets induced

\footnotetext{
${ }^{2}$ This deregulation has been continually criticized by firms that use the regulated lines, and created a controversy between regulated firms and the users of their facilities. For example, in December 2009, Cbeyond.Inc, supported by the Small Business Administration (SBA), filed a petition with the FCC to reverse the deregulation. In response to this, the Telecommunications Industry Association (TIA) and the Fiber-to-the-Home (FTTH) Council in January 2010 jointly filed with the FCC not to reverse the deregulation. Similar disputes exists in Asia and Europe. For example, the Japanese government is considering joint managment of fiber-optic networks within all related firms. In Australia, the largest telecom company, Tlesta, declared that they will not build fiber networks if the regulation is enforced.
} 
by unbundling increased social welfare. However, the effects of unbundling on infrastructure construction markets is not considered well. To reveal the effects on infrastructure construction of unbundling, the Japanese experience was an important episode. In 20052009, Japanese government continued the unbundling regulation on new fiber-optic lines in the diffusion periods of fiber-optic network construction. In the process, cable television and electric companies have reduced or stopped building their fiber lines. They claimed to regulators that the unbundling decreased their incentives to build their own lines. This is due to their lost of potential customers to the unbundling user firms, and also to intense price competition with unbundled firms. As a result, in Japan, regulated firms have dominated the infrastructure markets with the increase of unbundling usage, and regulators failed to accelerate competition in building fiber-optic networks.

Using this phenomenon and the data sets, this paper analyzes unbundling regulation effects on the entry decision of new firms in building networks, and gauges the regulation's effects on competition in the building of infrastructure. In this paper, we show the effects of unbundling usage on cable television's entry decision on the fiber network construction using linear regression and probit estimation. Second, this paper models the dynamic game of infrastructure construction and estimates the effect of unbundling on the profits of new entrants. To evaluate how unbundling affects the infrastructure construction, we need a dynamic model of entry. New firms enter the market considering future profits because it takes a huge initial investment to build the fiber lines. In both cases, we find the negative effects of unbundling on entry decisions due to profit decrease. This finding suggests that unbundling regulation during periods of new technology diffusion decreases competition in the infrastructure market.

This paper proceeds as follows. Section 1 overviews related literature. Section 2 discusses unbundling regulation and what happened in the infrastructure competition in the fiber penetration in Japan. The data sets to be used in this study, their management 
and their characteristics are presented in Section 3. In Section 4, the evidence from linear and probit estimation is provided. The model of dynamic game of infrastructure competition and the estimation identification is discussed in Section 5, and Section 6 concludes.

\section{Previous Related Literature}

Theoretical papers about local loop unbundling regulation analyzed its price and usage effects on the installment of infrastructure. Jorde, Sidak and Teece (2003) found that the usage of unbundling will decrease investments, and Bourreau and Dogan (2005) and Hori and Mizuno (2006) considered regulation-price effects on the infrastructure competition. These theoretical papers suggest that unbundling regulation reduces investments and competition in infrastructures. On the other hand, Cave (2006) claims that unbundling increases the investment of carriers.

In empirical papers, the literature considered the pros and cons of unbundling regulation on society. As positives, Greenstein and Mazzeo (2006) found that unbundling widened the variety of services in the telecommunications industry. Economides, Seim and Viard (2008) found that competition induced by unbundling increased social welfare. Conversely, Crandall, Ingraham and Singer (2004) showed that existing telecommunication carriers decrease their own investments by unbundling policies.

This paper is different from the literature above because of the following reasons: First, we identify that unbundling regulations prevent new entry in the facility market. Previous literature mainly focuses on the service markets. This paper gauges the effects of how unbundling regulation to foster competition in service markets changed the competition in different markets. We find that regulation increases the regulated firms' share

paradoxically, even though it aims to weaken those firms. Secondly, we use the events of 
installing new technology to identify the effects. The installment of fiber-optic lines to the home is a good case to check the regulation effects: entrants constructing new fiber lines needs a significant amount of money, and we can observe those behaviors clearly. Furthermore, policy makers are currently debating whether to keep the regulation on fiber premises or not. In Japan's case, "free and fair" competition in service markets, induced by unbundling, destructs facility competition. Third, because entry decision in telecommunications is based heavily on dynamic behaviors, this pape $\mathrm{r}$ estimates the effects using structural dynamic models.

\section{Local Loop Unbundling and the Diffusion of Fiber- Optic Networks in Japan}

\subsection{Telecommunications Act of 1996 and Export of US Un- bundling Regulation}

In 1996, the FCC (Federal Communications Commission), under the Clinton Administration started the Telecommunications Act of 1996. This law aims to promote new entries and competition in the communication industry, mainly by the unbundling regulation. Unbundling requires specific existing carriers with local premises to lend their facilities to any competitors at a regulated low price. This law enables the firms without facilities to enter the industry easily, and solves the problem of natural monopoly. Literature shows that, as a result of fair competition, unbundling decreases prices, increases a variety of services, raises consumer welfare, and provides high quality services, all of which are positive contributions to society. Vogelsang and Mitchell (1997) summarizes the regulation.

In 1998, unbundling regulation was exported outside the United States. Under the 
WTO telecommunications law, unbundling is approved as accelerating free and fair competition in telecommunications. Similar regulations are imposed in more than 80 countries over the world.

In the U.S., however, regulated firms brought many suits on the regulations. They claimed that it decreased the investments of regulated firms, weakened facility-based competition, and infringed upon their property rights. In response to these claims and judicial decisions, the FCC amended some of the regulations. Particularly, the FCC confronted the delay of prevalence of fiber to the home (FTTH) and aimed to speed up the diffusion. In contrast, regulated carriers insisted that unbundling regulation deterred their investments on building fiber-optic networks. To encourage the diffusion of fiberoptic networks, the FCC in 2003 decided to remove unbundling regulation on fiber lines.

Whether this decision by the FCC was good for social benefits is still under discussion. In the contrast to era of Telecommunication Act of 1996, when regulated firms complained, at present the user firms of unbundling regulation are petitioning to the FCC to reverse the deregulation on unbundling on fiber lines.

\subsection{Diffusion of Fiber-Optic Networks and Battles over Un- bundling in Japan}

Unlike the United States, Japan is among the countries that faithfully adheres to the unbundling regulation of the WTO agreement on both fiber and metal lines. In Japan, Nippon Telegraph and Telephone Corporation (NTT) is defined as a unique regulated carrier. NTT was a government-owned telephone company, until privatization in 1985, and remains the world's largest group in the telecommunication industry. NTT inherited numerous metal telephone lines from the government. Unbundling regulations started in 1997, and the Telecommunications Business Act in Japan strictly enforced a NTT 
to lend their local and relay lines, both fiber and metal, to all other firms at a low government-decided rental price.

The diffusion process of fiber networks (fiber to the home (FTTH)) in Japan can be roughly divided into three stages. First, in the early 2000s, NTT's FTTH's share was low. In March 2002, its share was 25.6\%, but cable televisions (CATVs) and electric companies provided strong competition. NTT had metal telephone lines, CATVs had metal CATV lines, and electric companies had their own electric lines. Therefore, for NTT, CATVs and Electric companies, it was easy to install fiber-optic lines next to their pre-exiting lines. CATVs and electric companies entered the fiber market to earn profits from services such as high quality IP-phone, high definition TV programs, and high speed internet. During this period, NTT's competition thought that unbundling regulation was preferable because it decreased NTT's investment on fiber networks, which in turn would allow their competitors' shares in the fiber market to increase.

However, in the middle of the decade, CATVs and electric firms decreased their investments or resigned to build in fiber networks (FTTH), because non-facility firms entered into the market using NTT's premise. These new firms took CATVs' and electric companies' potential customers. Also, even if CATVs build their own fiber lines, they will be among harsh price competition with NTT that has to share lines at regulated low cost. Furthermore, the user firms strongly demanded the government reduce the rental price and flexible usage of the facility: user firms estimated and claimed the rental cost at 690 Yen (7.6 USD) per fiber line a month, but it was significantly different from the government-decided / NTT's claimed rental cost of 5094 Yen (56.6 USD). Conflicts on the conditions and prices of fiber lines between the NTT and user firms, involved Ministry of Internal Affairs and Communications (MIC), Japan Fair Trade Committee (JFTC), courts, politicians, consultants, lawyers, and economists. In the battles between NTT and user firms, CATVs and electric companies always filed petition and claimed to 
MIC that the unbundling regulation decreased their incentive to enter the fiber-optic line market and increase investment. They claimed that unbundling only favors the service market in allowing "fair" competition, but negatively affects competitors in facility-base markets.

Finally, by the end of the 2000s, NTT's share of fiber lines was around $75 \%$, and they dominated the fiber facility market, eliminating other firms under unbundling regulation. Also, a few CATV started to borrow the fiber lines from NTT, rather than build lines themselves. ${ }^{3}$ This market structure was heavily criticized by both user firms and facility competitors faced with a monopolistic situation. The MIC is currently discussing to deprive the operation of fiber lines from NTT. However, NTT and their stockholders are heavily opposed to the idea because they have already used 2.7 trillion yen to install fiber lines, and the infrastructure is one of the important sources of profits for NTT.

This paper assesses numerically whether unbundling regulation prevents new entries in the facility market and whether it induces monopolization.

\section{Data Description and Variables Construction}

\subsection{Data Sources}

This paper uses four data sets and matches them in a municipal level for analysis. The first data is unbundling regulation usage data. NTT East, a unique, regulated carrier in eastern Japan, provides data of the number of companies that used NTT's fiber-optic facility in station level between 2005 to 2009. The number of stations that NTT modified

\footnotetext{
${ }^{3}$ In general, CATVs do not share their lines to other firms. This is because there is little scale economy in CATV's industry and their size is small. So, if user firms want to borrow lines from CATVs, they have to negotiate for each user firms' customer. This cost significantly large transaction cost. Electrics companies offer a little bit wider area and they lend their lines to other firms. However, compared to NTT and government regulation system, their shared line is little.
} 
to the fiber lines is also taken from this data.

The second source is the entry and exit data of fiber-optic network (FTTH) building markets. The Ministry of Internal Affairs and Communications (MIC), a Japanese regulation authority, provides an information and communications statistics database. Using these figures, we can detect which company built the fiber-optic premises between a station and a home in an prefecture of monthly interval. Therefore, we can identify when, where, and which firms built the fiber-optic networks (FTTH).

The third data are figures that examine CATVs and their coverage area. The Regional Broadcasting Division in the MIC provides facility data of CATVs in a municipal level. Using this data set, we can identify which CATVs enter which market. Combined with the second FTTH data set, we can deduce which CATVs built fiber-optic networks (FTTH) in which markets. Most firms that build fiber-optic networks provide HDTV programs via fiber line, so the data includes firms such as TEPCO (operated by The Tokyo Electric Power Company) and JCN (operated by KDDI), which do not specialize in CATV.

The fourth source is market characteristics data. We use population, population density, and income at a market level. The population and density data is taken from the 2005 Census, and income data is taken from a tax division of the MIC.

\subsection{Construction of Variables}

\subsubsection{Definition of Market}

This paper combines the aforementioned four data sets in a municipal level. The municipal is the smallest definition of a market that we can construct using public data. The data follows the definition of municipal in April 2009. 962 municipals exist in east Japan in April 2009, and the average number of household is 25,924. (maximum is 40,910 and

\footnotetext{
${ }^{4}$ There are many mergers of municipals in Japan from 2005-2009
} 
minimum is 131$)^{5}$ The reason we use the municipal level data is twofold: First, in our model of dynamic entry game, we assume symmetric firms. If we use a larger definition than a municipal level, it is possible that the assumption of a symmetric firm size is false. For example, if we use a larger definition of a market, it is possible that 10-20 CATVs enter in one market, but their actual sizes might be very different. If we divide large firms with small areas, we can assume similar symmetric size in the area. Most markets contain zero to two CATVs. Second, this paper considers competing networks between CATV firms. In other words, we assume consumers can choose fiber-optic lines from a few options, such as one NTT and one or two CATVs. If we use a larger data size, the consumers' choice set is different from an actual one. Using the municipal market definition, in more than $95 \%$ of market, the consumer has to choose between two CATVs or less, and this is plausible, considering the actual consumers' choice set.

\subsubsection{Usage of Unbundling Regulation}

One of the key variables in this paper is the usage of unbundling regulation. NTT East advertises the number of firms that used their fiber facilities. Because we cannot get the direct quantity data in each market, we used this number as a measure of unbundling regulation usage. We take two variables from this data set: usage of "station to home" and usage of "station to station" fiber-optic network. The "station to home" usage is our most concern, which is the usage of fiber optic networks (FTTH) between the core network to the home/office. In each market there are several stations (average is 3.67). The maximum number of usage firms for the station in the market are taken as the market's usage measure, assuming several firms enters in all markets. We guess there is a positive correlation between the usage and the number of families: in a large market, the number of firms which uses the NTT's facility will increase. To account for this,

\footnotetext{
${ }^{5}$ We excluded Niigata and Kamiku Isshiki because they do not fit the definition of a municipal market in April 2009.
} 
we divide the number of firms by the number of families. Therefore, in this paper, the number of usage firms per household is the measure of the market's usage level of unbundling regulation in the market.

The regulation system of unbundling itself is the same all over eastern Japan: NTT has to lend all their facilities to every applicant at the same rental price determined by the regulation authority. However, the usage level is different in each market. There are several sources that contribute to this variety. First, the regulation price is fixed in all markets; however, the actual rental price could be different in each market. In general, the price in a urban area is higher than a rural area, so the real rental price is relatively lower in the urban area. Furthermore, the cost to build a fiber-optic network is also different in each market. It costs a lot to build a fiber-optic network in some rural areas that have low population densities or are isolated by mountains or seas. Even in some urban locales, if the telephone/CATV lines are underground, the cost of building a fiber-network is higher compared to installation via telephone poles. Therefore, in low real rental price markets, firms easily use NTT's premises and the number of usage firms will increase. So, the usage level is different due to actual price. Second, the usage demand of consumers are different in each areas. In general, NTT's facilities are provided to all companies, whereas non-NTT facilities are self-used. If a city has popular community-based TV programs or ISPs, then those firms may increase NTT's usage. Third, the procedures and connection condition is also different in each market. In a discussion between NTT and user firms, an argument ensued about problems such as how promptly NTT should react to user firms' applications. These factors may also affect the usage-level variety.

\subsubsection{Building Fiber-Optic Networks}

In this paper, the main interest is to analyze if CATVs built their own fiber networks between station to home (FTTH). The fiber network backbone had been installed all 
over Japan more than ten years ago. However, with metal lines, the data transfer rate decreases exponentially with the from the core network. Comparably, with fiber-optic lines from core network to the home/office, the transfer rate reduction disappears and a high data transfer rate is maintained. The line between a station to a home is called the "last one mile," (the distance a station can cover is approximately one mile.) In the process of building fiber-optic networks, installing this "last one mile" makes up a large part of cost. Therefore, this installment is of much interest to policy makers.

Which and where CATVs build fiber-networks is recorded by MIC. Information and Communications Statistics Database in the MIC maintain records for which companies build networks in which prefecture. Also, the MIC's Regional Broadcasting Division Database can identify in which municipal the CATVs operate. By connecting these two, we can observe when and in which market CATVs built a fiber-optic network. Because we only have firm/prefecture level fiber-optic entry and municipal level CATV activity, we assume that CATVs decide to enter the prefecture level on their own networks. Since most CATVs cover a few markets, we think this a plausible assumption.

NTT, the dominant carrier, also built a fiber-optic network which covered most of Japan: NTT did not offer coverage to only 2 out of 962 markets in eastern Japan. NTT's data set show how many stations they installed with fiber optics. This number of stations correlates to the number of fiber-optic lines. However, the number of stations depends on both the number of lines and the population density. More stations are needed in a low density area than a high density area, even if the number of lines offered are equal. Considering this aspect, we divided the number of stations by population density, and use the number of stations per density as a quantity measurement of NTT's optical fiber lines.

The fiber-optic network technology is different between CATVs and NTT. CATV's main technology utilizes both Hybrid Fiber Coaxial (HFC) and Fiber To The Home 
(FTTH). The Hybrid Fiber Coax is similar to FTTH. The difference lies in that the HFC uses fiber lines to connect the core network to a building area, and then uses the metallic lines after this point, while the FTTH uses fiber lines entirely. The HFC has a slightly lower data transfer rate than the FTTH, but both offer similar speed. For example, in June 2010, the NTT's FTTH offered 200 Mbps at 6720 yen and J:COM (CATV) offered 160 Mbps at 6300 yen in Tokyo.

\subsubsection{Market Characteristics}

Because the decision of building the fiber-optic network also depends on market factors, we used several market characteristics variables. We took two categories: demand and cost. As demand factors, number of households, number of people per household, and average income are taken. We also used population density as cost factors of the market. Year dummies are added because the regulated price and building technology changes with time, and also spurious relationship exits in variables. The number of households is to measure the potential lines in the market. Ordinarily, the fiber lines are installed one line per household. The number of people per household is defined by population divided by number of households. This variable represents the characteristics of households: large households may want to install fiber lines more than small households. The average income, defined as aggregate income divided by population in each market, shows the richness of the market; richer markets may have more demand on fiber-network premises. The density is population divided by area in each market. It costs more to install lowerdensity markets. All market variables are fixed in one year, because it is difficult to get the data with time and also do not change much from year to year. In the estimation of dynamic game, we can reduce the state space by fixing unchangeable variables. We took from the 2005 Japanese census the number of households, number of people per household, density, and average income of the market. The income is taken from the tax 
division in the MIC of 2008. To adjust the unit problem, we divide all market characteristics by the mean of the variable. Assuming the effects of these market characteristics are concave, we take a log of all variables, after adding 1 to avoid an infinity problem.

\section{Evidences and Identification}

\subsection{Linear Regression Models}

First, this paper considers whether the usage of unbundling affects the entry share of CATVs into the fiber optic networks market, using linear regression models. We assume the following estimation equation

$$
y_{m t}=\beta_{0}+\beta_{1} \times \text { usage }_{m t}+\beta_{2} \times \text { station }_{m t}+\mathbf{X}_{m t} \beta_{3}+d_{m}+d_{t}+\varepsilon_{m t}
$$

where $y_{m t}$ is the percentage of CATV firms that build the fiber-optic lines (the number of CATVs, that build fiber-optic networks divided by the number of all CATVs), usage $e_{m t}$ is the number of firms per household that used the NTT's regulated facility between station to home, which is our interest. ${ }^{6}$ station $_{m t}$ is the number of the stations which NTT adopted the fiber-optic lines. We use this variable as the measurement of quantity of NTT's line. This variable is for distinguishing the usage effect from NTT's competitor effects. $\mathbf{X}_{m t}$ is market characteristic variables: number of households, number of people per household, average income and density. $d_{m}$ and $d_{t}$ are the market and year dummy.

Considering the endogeneity of $u s a g e_{m t}$, we used the number of firms which used the regulated facility between station to station as the instrument. When firms with no

\footnotetext{
${ }^{6}$ We divided by number of households, because oftenly when number of households increase, number of user firms increase. However, there are possibility the divsion of family caused the negative effetct, because the number of user firms increase concavely. We consider the effects and checked robustness using original firms number and exponental conversion. We confirmed the significant negative effects.
} 
facility typically enter into the market, they use both station to home facility and station to station facility. Some firms use just station to home lines; these are called bottleneck facility, because some of them have station to station facility. Therefore, the usage of station to station facility is related to the usage of station to home facility. However, the decision of CATV firms as to whether they build the line between station and home should be unrelated to the usage of the facility between station and station, because the station to station usage will not substitute the lines between home and station. We use this as instrument variable and estimated the estimation equation. ${ }^{7}$

Table 8 depicts the results of linear regression model. This table reports whether the unbundling usage of NTT facility decreases the entry share of CATVs in building fiberoptic networks. The first column is ordinary random-effects GLS regression. The usage has no significant results. CATVs will enter in the earlier stage considering the future profits, rather than later stage. The second column estimates allowing the endogeneity of usage, using 2SLS random-effects IV regression. NTT's competitor effects become significant, but we cannot observe significant usage effect. The third column shows the results of random-effects tobit regression. In this regression, we consider the censored data effects. The entry share (fiber CATVs divided by all CATVs) should takes between 0 and 1 from its definition. Considering these effects, we used a tobit model. This estimation does not consider the endogeneity because of limitation of tobit regression. The tobit regression's result shows the usage is significantly negative. Therefore, we observed the usage of NTT facility decreases the CATV's entry share in building fiber-networks.

\footnotetext{
${ }^{7}$ The vailidity of instruments may arise. There is possibility of the inverse causality that NTT's construction of fiber decrease the usage of station to station. Considering about the instrument vailidity, we are planning to add past usage of station to home as instruments in the future.
} 


\subsection{Probit Models}

Next, using the discrete choice model, we consider how much the usage of unbundling affects the number of entry of CATVs to fiber-optic networks. We consider entry decisions using probit and bivariate order probit models. First, we assume following estimation equations with an IV probit model and consider the causality of usage on building fiberoptic networks.

$y_{m t}=1\left(y_{m t}^{*}=\beta_{0}+\beta_{1} \times\right.$ usage $_{m t}+\beta_{2} \times$ Incumbent $_{m t}+\beta_{3} \times$ station $\left._{m t}+\mathbf{X}_{m t} \beta_{4}+d_{t}+\varepsilon_{m t}>0\right)$

where $y_{m t}$ takes 1 if there is entry in the fiber-optic building market, otherwise 0 . Other variables are almost all the same and I used the same instruments with the linear regression model. Also, I added the number of current incumbents of the market that built the fiber-optic lines $\left(\right.$ Incumbent $_{m t}$ ), and could not enter the market dummy compared to linear regression model because we used the instrument in the probit model.

Next, we confirm the effect of usage using a bivariate ordered probit model. The bivariate ordered probit model also can solve the endogeneity problem. We assumed the following estimation equations:

$$
\begin{aligned}
y_{m t} & =1\left(y_{m t}^{*}=\mathbf{X}_{m t} \beta_{0}+\beta_{1} \times \text { station }_{m t}+\beta_{2} \times \widehat{\text { usage }}_{m t}+d_{t}+\varepsilon_{m t}>0\right) \\
{\widehat{\text { usage }_{m t}}} & \left.=1{\widehat{\text { usage }_{m t}^{*}}}^{*}=\mathbf{X}_{m t} \beta_{0}+\beta_{1} \times \text { station }_{m t}+\beta_{3} \times \text { Instrument }_{m t}+d_{t}+\mu_{m t}>0\right)
\end{aligned}
$$

where $y_{m t}$ is the entry of CATV firms that build their own optical fiber network. $\widehat{\operatorname{usage}}_{m t}$ is the number of firms that used NTT's facility. This is similar to previous 
usage $_{m t}$ but we discretise it in 7 bins to estimate by ordered probit model. Instrument $_{m t}$ is the same with a linear regression model. Other variables are the same definition. Our previous concern was the endogeneity between $y_{m t}$ and $\widehat{u s a g e}_{m t}$, and the correlation between $\varepsilon_{m t}$ and $\mu_{m t}$ causes the bias. In this model, we simultaneously estimated the two probit/ordered probit models using a bivariate ordered probit model, allowing the correlation between $\varepsilon_{m t}$ and $\mu_{m t}$, and solving the problem.

Table 9 denotes the results of probit models. We could not add the market effects for IV or ordered probit model's estimation limitation. The first column estimates the effects of the usage on whether CATVs enter in fiber-networks or not, using IV probit model. We observed that the usage decreased the entry significantly. The second and third columns are the results of bivariate ordered probit model. By simultaneously estimating the ordered probit model, we get the true effect of removing the bias caused by endogeneity. The results also suggest that the regulation usage decreased the number of CATVs that build fiber-optic networks.

\section{Unbundling Effects on the Dynamic Behaviors of New Entrants}

\subsection{Structural Dynamic Entry Game Model}

In comparison to the above, in this section we consider a structural dynamic entry game. By modeling the competition in building fiber-optic networks using dynamic game, we get several good features. First, in the model of dynamic game, we can estimate dynamic behavior of firms. The telecommunication industry has natural monopolistic characteristics for its huge, sunk, up-front and fixed costs. The entrants consider future profits and make the decision to build the fiber-network facility over the long term. In the dynamic 
model, we can model this aspect, compared to static models. Second, by this dynamic structural estimation, we can estimate unknown parameters that ordinary estimation methods cannot get. We have only entry and exit data of fiber-optic network, usage of unbundling regulation, and market characteristics in market level. Using that data, we confirmed the effects of regulation on the entry share and the number of entries in previous models. However, by adding a bit of economic assumptions, we can estimate the profit function and sunk cost of entry. These estimates have important values for designing regulation and considering the social impact of the regulation on fiber-optic diffusion and competition. Furthermore, we can value the policy change by counter-factual simulation using the getting parameters. ${ }^{8}$

\subsection{Framework}

There are $m \in\{1,2,3, \ldots, M\}$ independent geographic markets and $t \in\{1,2,3, \ldots, \infty\}$ discrete infinite time periods. The unit of $m$ is municipal and the one of $t$ is one year. There are two type of players $\tau \in\{C A T V, N T T\}$ : one dominant carrier, called NTT, and $N_{m}$ CATV firms compete to build "station to home" fiber-optic network in the market $m$. (This game is a Mazzeo (2002) type (2 type competition) dynamic game.) CATVs decide whether to build fiber-optic station to home lines to their clients or not, while NTT decides whether build station to home fiber-optic lines in its stations or not. Because the exit from offering fiber-optic network is very rare, we limit the firms' option as whether they enter or not. (We deleted the markets where a firm quit offering a fiber-optic network.)

The timing of the game is as follows. First, at the beginning of each time period t, NTT and CATVs observe: 1.) the number of CATVs that have already constructed fiber-optic networks; 2.) the number of stations for which NTT has already adopted a

\footnotetext{
${ }^{8}$ In the future revision, we are planning to conduct this.
} 
optical fiber network; 3.) usage of NTT's facility by user firms; 4.) market characteristics; 5.) market fixed effect and 6.) current year. Second, CATVs decide whether they build the fiber-optic network in the market and NTT decides whether they build its fiber-optic network in additional stations, simultaneously. Third, entrant CATVs pay costs, and NTT also pays a cost if they decide to increase lines (stations) for fiber-networks. At the end of each period, incumbent CATVs get profits and NTT also gets proportional to its station. After the realization, market states evolve to next period. We should keep in mind that this model assumes a one year "time-to-build": the entrants pay the building cost at time $t$, but they will earn profits after $t+1$.

\subsection{State and Action Variables}

Considering the competition of building fiber-optic networks and applying it to the model, we define here five state variables. Observing these state variables, CATVs and NTT decide to build fiber-optic networks. The five state variables are the number of fiber-built CATVs, the number of fiber-built NTT stations, usage of NTT facility, market dummy and year dummy. We fixed the other market characteristic variables such as number of households, density and income, because they will not change much over time and we can decrease the state space. In this paper, we assumed the number of fiber-built CATVs and the number of fiber-built NTT stations as endogenous state variables for which the model determines the state. We also assumed usage of NTT facility, market dummy and year dummy as exogenous state variables, for these states variables evolve outside the model. We discretise the variables to reduce the state space: number of NTT's fiber-built stations for 4 bins, usage for 7 bins. The state of number of fiber-built CATVs are 3 . (0, 1 and 2) I also constructed 4 market dummy and 4 year dummy. Therefore the total state space is $3 \times 4 \times 7 \times 4 \times 4=1344$.

We assume action variables are binary. For CATVs, it is whether they build station to 
home fiber-optic networks for their clients. For NTT, it is whether they increase station to home fiber-optic stations. In the most markets, CATVs did not exit fiber-optic network service and NTT did not decrease the fiber-station. We can assume CATVs do not exit and NTT does not disinvest. We deleted markets in which CATV exited or NTT disinvested.

\subsection{Unobservable Heterogeneity}

One of the important concerns of the relationship between CATV's entry and usage of NTT's facility is unobservable heterogeneity. If there are some unobserved market characteristics, the estimated results are biased. For example, if for some reason markets have difficulty installing fiber-network facilities, this causes an increase of installed lines' usage and a decrease of entry of CATVs. To avoid this unobserved market heterogeneity, we inserted the market fixed effect variables. To address this, we used a two-stage fixed approach. This is similar approach with Aguirregabria and Ho (2009), Collard-Wexler (2006) and Lin (2009). First we take the average entry number of fiber CATVs and NTT's fiber station for each market. By regressing them of market characteristics, we get residuals of each market. We discretised the residual for four bins, and get three dummies to adjust the level of unobserved profitability. In the second stage, we added the three dummies to the per period payoff function to remove the unobserved heterogeneous bias.

\subsection{Spurious Relationship}

In the diffusion process, key variables such as usage of unbundling, NTT's fiber station and entry of CATVs increased simultaneously. We may have another concerns on the spurious relationship. To remove this effects, I added year effects in profit function as endogenous variables. It increases with year and stops in 2009. We can evaluate the 
usage effects avoiding year effects by this.

\subsection{Per Period Payoff Function}

We assumed linear and reduced-form payoff function. Linear forms require less computing time and these assumptions are also common in other papers.

$$
\pi_{i m t}^{\tau}=\underbrace{X_{m t} \beta_{X}}_{\text {Revenues of FTTH service }}-\underbrace{Z_{m t} \beta_{Z}}_{\text {Costs of FTTH service }}-\underbrace{g\left(N_{-i m t}^{\tau}, N_{-i m t}^{-\tau}\right)}_{\text {Competitors' effect }}-\underbrace{G_{m t} \beta_{G}^{\tau}}_{\text {Regulated usage effect }}
$$

where $X_{m t}$ is demand factors of the market (number of firms, number of people per household and average income), $Z_{m t}$ is cost factors of the market (density), $g\left(N_{-i m t}^{\tau}, N_{-i m t}^{-\tau}\right)$ is the competitors' effect of similar services (number of other CATVs that provide fiberoptic services and number of fiber stations of NTT), and $G_{m t}$ is the unbundling regulation effects. We took facility usage of NTT firms. We used number of firms which used NTT's facility as measurement. In this paper, we assume CATVs are symmetric and the size of NTT's stations are also identical. These firms conduct Cournot type competition, and the regulation access rates' effects has already reflected the usage of unbundling regulation. We assumed firms pay sunk cost to enter, and get zero profit if they do not enter.

On the competitor effect $g\left(N_{-i m t}^{\tau}, N_{-i m t}^{-\tau}\right)$, we didn't assume the proportional effects because the first competitor's effect is larger than the second competitor's in CATVs competition. We also assume the CATV's entry affects NTT's decision, and NTT's construction affects CATV's decision. Reflecting these, the function of $g\left(N_{-i m t}^{\tau}, N_{-i m t}^{-\tau}\right)$ becomes the following: 


$$
\begin{aligned}
g^{\tau}\left(N_{-i m t}^{\tau}, N_{-i m t}^{-\tau}\right) & =\beta_{1}^{C A T V} \times \text { presence of first CATV that constructed FTTH } \\
& +\beta_{2}^{C A T V} \times \text { presence of second CATV that constructed FTTH } \\
& +\beta_{3}^{N T T} \times \# \text { of NTT's fiber stations }
\end{aligned}
$$

\subsection{Firms Behaviors and Markov Perfect Equilibrium}

Under the above assumptions, CATVs and NTT simultaneously chooses their actions to maximize the present values of the sums of future profits. We can define value function as follows,

$$
V\left(S_{i t}\right)=\max _{a_{i t}^{\tau} \in A} E\left[\pi_{i t}^{\tau}\left(a_{i t}^{\tau}, S_{i t}\right)+\beta \int V\left(S_{i t+1}\right) d F\left(S_{i t+1} \mid S_{i t}, a_{i t}^{\tau}\right)\right]
$$

where $a_{i t}^{\tau}$ is an action variable of firm $i$, type $\tau$ and time $t . S_{i t}$ is the state variable for firm $i$ and time $t$. Following previous literature, we take the discount factor $\beta$ as 0.95 because the data is annual. A Markov strategy is a mapping $\sigma_{i}\left(S_{i t}\right) \longmapsto\{0,1\} \in A_{i t}$, where $A_{i}$ is the firm's action set. If CATV firms enter in or NTT increased the fiber station, it is 1 ; otherwise, 0 .

We can rewrite the above value function, conditional on the strategy,

$$
V\left(S_{i t} \mid \sigma\right)=\max _{a_{i t}^{\tau} \in A} E\left[\pi_{i t}^{\tau}\left(\sigma, S_{i t}\right)+\beta \int V\left(S_{i t+1} \mid \sigma\right) d F\left(S_{i t+1} \mid S_{i t,} \sigma\right)\right]
$$

Then a set of Markov strategy $\left(\sigma^{*}\right)$ is a Markov Perfect Equilibrium if and only if,

for all $i, S_{i t}$, and alternative strategy $\sigma_{-i t}^{\prime}, \sigma^{*}$ satisfies

$$
V\left(S_{i t} \mid \sigma_{i t}^{*}, \sigma_{-i t}\right) \geq V\left(S_{i t} \mid \sigma_{i t}^{\prime}, \sigma_{-i t}\right)
$$




\subsection{Exogenous Transition Probability}

Endogenous state variables, number of fiber-built CATVs, and number of fiber-built NTT stations, evolve within the model and their transition probabilities are determined by rational profit maximizing behavior of CATVs and NTT. Compared with these, usage of NTT facility's transition probabilities, market dummy and year effect are determined exogenously.

First, we construct the transition probability matrix of usage of NTT fiber lines from actual movement. Each element of transition probability is calculated from the following equations using actual observations. These calculations are similar to Dunne, Klimek, Roberts and Xu (2009) or Elejalde (2009).

$$
\widehat{\operatorname{Prob}}\left(\text { usage }^{\prime} \mid \text { usage }\right)=\frac{\sum_{(m, t)} 1\left(\text { usage }_{m, t+1}=\text { usage }^{\prime} \text { and usage } \text { ust }_{\text {s }}=\text { usage }\right)}{\sum_{(m, t)} 1\left(\text { usage }_{m, t}=\text { usage }\right)}
$$

In this dynamic game settings, we assume that CATVs and NTT perfectly predict the future usage of NTT facility and decides their entry decisions.

Second, we assumed market dummy is fixed over the year, and it does not change. Also, year effects increase with time, but stop in 4 years after. These transition is common knowledge for players.

\subsection{Estimation Methodology}

In this paper, we used Aguirregabria and Mira (AM) (2007)'s Nested Psuedo Likelihood estimation (NPL). The estimation methodology is the refinement of Hotz and Miller (1993)'s 2-step type Psuedo Maximum Likelihood Estimation (PML) by Aguirregabria and Mira (2002). AM(2007) has robust characteristics with small sample bias and it can estimate under the multiple equilibrium. 
The value function is defined as

$$
V\left(x_{t}\right)=\int \max \left\{\pi\left(x_{t}\right)+\epsilon_{t}\left(a_{t}\right)+\beta \int V\left(x_{t+1}\right) d F\left(x_{t+1} \mid x_{t}, a_{t}\right)\right\} g\left(d \epsilon_{t}\right)
$$

From action observable, we can construct $\mathrm{CCP}$ (conditional choice probabilities),

$$
p_{i t}^{\sigma_{i t}}\left(a_{i t} \mid x_{t}, \epsilon_{t}\right)=\operatorname{Pr}\left(\sigma_{i t}\left(x_{t}, \epsilon_{i t}\right)=a_{i t} \mid x\right)=\int I\left(\sigma_{i t}\left(x_{t}, \epsilon_{i t}\right)=a_{i t}\right) d F\left(\epsilon_{t}\right)
$$

$\mathrm{I}($.$) is the indicator function, and we assume \epsilon_{t} \sim N(0, \Omega)$.

Nested Pseudo Likelihood estimator is calculated using the following procedures.

Step 1: Set initial probability. We took nonparametrically the initial CCP from the data set, following $\operatorname{AM}(2007)$, as

$$
\widehat{P^{0}}\left(a_{i t} \mid \bar{x}\right)=\frac{\sum_{t} \sum_{i} I\left(a=a_{i t}, x=\bar{x}\right)}{\sum_{t} \sum_{i} I(x=\bar{x})}
$$

Step 2: Given a $\operatorname{CPP}\left(P^{k}\right)$, construct the pseudo maximum likelihood function and get the $\theta^{k+1}$ by maximization

$$
\theta^{k+1}=\arg \max _{\theta \in \Theta} \sum_{m} \sum_{t} \sum_{i} \ln \Psi\left(a_{i m t} \mid x_{i m t}: P^{k}, \theta\right)
$$

where $\Psi$ is the choice probability function.

Step 3: Based on $P^{k}$ and the $\theta^{k+1}$ in the step 2, update the probability function according to

$$
\widehat{P^{k+1}}\left(a_{j} \mid x\right)=\Psi\left(a_{j} \mid x_{i m t}: P^{k}, \theta^{k+1}\right)
$$

for all $a_{j} \in A$ and $x \in X$. 
Step 4: Continuously updates Step 2 and Step 3 till $\theta$ 's distance converges. We took the criterion to $1 \mathrm{e}-3$.

These are direct application of $\mathrm{AM}(2007)$.

\subsection{Implication}

Table 10 shows the estimation results of the dynamic structural model. The usage-effect coefficients on CATVs' profit were significantly negative, and on NTTs' profits were significantly positive. The results find that the regulation usage decreased the CATV's profits on building of fiber-optic networks, therefore it decreases their incentives of CATVs to enter the markets via profits as reduced form results suggest. Compared to this, NTT's profits will increase if the unbundling usage increase, and they have incentives to increase their fiber by unbundling regulations. (This suggests that NTT can make more profits in infrastructure markets if it lends to unbundling regulation users. However, this does not necessarily imply the increase of total profits of infrastructure and service markets.)

For further analysis, we can improve or expand the results. We divided the market dummies by four, due to the state space problem, but more smooth adjustment will improve the estimates like sunk cost of NTT and market characteristics, which are the different sign with our prediction. Also, using this values, we can evaluate counter-factual analysis on policy issues:how many CATVs build their own fiber lines if regulators quit unbundling like FCC in the US.

\section{Conclusion}

This paper studies the effects of competition law on other related markets that are not targeted by the law. One of important analyses on unbundling regulation is the 
effects on compentition structure in infrastructure markets, which previous literature have not studied well. This paper identified the effects using unique events of fiber-lines infrastructure formation, and estimated how the unbundling regulation usage changed the CATVs' entry behaviors. Japanese data set is utilized because it has experienced fiber lines penetration and continued unbundling regulation, in contrast with other countries.

This study finds that the unbundling regulational usage block new entry and has monopolization effects for regulated carriers on building fiber-optic networks. Using the entry data of CATV firms in building fiber-optic networks and the usage data of regulated fiber-optic facilities, this paper structurally estimates the profit function and the entry sunk cost, assuming dynamic entry game. Estimation results suggest that the regulation reduces the profit of new entrants, and prevents to build their own fiber-optic networks. Quitting to build their own lines is fatal decision for CATVs because they may go extinct in the near future if they cannot offer high speed internet or HD TV programs via fiber lines. ${ }^{9}$

As a policy implication, this paper suggests that there is a possibility that competition law distorts market discipline and reduce the competition in related markets. New firms enter markets seeking monopolistic profits. If regulations remove the monopolistic gains, firms will not enter the markets. As an example, unbundling regulation is the doubleedged sword. It may lower the price in service markets. However, in the diffusion stage of new technology, unbundling regulation strengthens the shares of regulated firms and may destruct competition in facility market. Japan was one of the ironic examples where the regulated carrier monopolized the fiber-optic facility market, whereas normally unbundling regulation removes "natural monopoly" of the lines.

This prevention of competition has a huge risk. For the next several decades, Japanese citizens may have to pay high maintenance fees to NTT, use the unwanted technology

\footnotetext{
${ }^{9}$ There is also possibility that those CATV firms borrow fiber lines from NTT and survive markets. But nobody knows the future.
} 
provided by NTT, and endure the narrow variety of connection services offered by the company. The Japanese government should work with NTT to decide the maintenance fees considering NTT's claims, user firms claims, and consumer benefits for the next few decades. Whether the benefits of the low unbundling price in the diffusion period outweighs the risks is still under question.

For the first time in half a century, countries all over the world are changing their metallic telephone lines to fiber-optic lines. Policy makers are required to make a big decision as to whether they will continue unbundling regulation on the new lines or not. The U.S. chose to abandon unbundling. Japan continued the regulation. Findings from Japanese experiences suggest that unbundling in technological change reduced competition in telecommunication facilities in order to gain fleeting benefits. 


\section{References}

[1] Aguirregabiria, Victor and Chun-Yu Ho 2009, "A Dynamic Oligopoly Game of the US Airline Industry: Estimation and Policy Experiments" Forthcoming, Journal of Econometrics

[2] Aguirregabiria, Victor and Pedro Mira 2002, "Swapping the nested fixed point algorithm: A class of estimators for discrete Markov decision models." Econometrica 70, 1519-1543.

[3] Aguirregabiria, Victor and Pedro Mira 2007, "Sequential estimation of dynamic discrete games." Econometrica 75, 1-53.

[4] Bourreau, Marc and Pinar Dogan 2003. "Unbundling the Local Loop," European Economic Review, vol. 49, pp. 173-199.

[5] Collard-Wexler, Allan. 2010, "Demand Fluctuations in the Ready-Mix Concrete Industry," Forthcoming, Econometrica

[6] Crandall, Robert W., Ingraham, Allan T. and Singer, Hal J. 2004 "Do Unbundling Policies Discourage CLEC Facilities-Based Investment?" The B.E. Journal of Economic Analysis \& Policy, Vol. 4, pp. 1-23.

[7] Dunne, Timothy, Klimek, Shawn D., Roberts, Mark J. and Xu, Daniel Yi. 2009 "Entry, Exit, and the Determinants of Market Structure," NBER Working Paper No. 15313.

[8] Economides, Nicholas, Katja Seim, and V. Brian Viard. 2008 "Quantifying the Benefits of Entry into Local Telephone Service." NET Institute Working Paper \#08-01, forthcoming, RAND Journal of Economics.

[9] Elejalde, Ramiro de, 2009. "Local Entry Decisions in the US Banking Industry" , mimemo

[10] Greenstein, Shane and Mazzeo, Michael. 2006 "The Role of Differentiation Strategy in Local Telecommunication Entry and Market Evolution: 1999-2002," Journal of Industrial Economics, v. 54, iss. 3, pp. 323-50

[11] Hori, Keiichi \& Mizuno, Keizo, 2006. "Access pricing and investment with stochastically growing demand," International Journal of Industrial Organization, Elsevier, vol. 24(4), pages 795-808, July.

[12] Jorde T.M., Sidak J.G. \& D.J. Teece 2000 "Innovation, Investment, and Unbundling", in Yale Journal on Regulation, vol. 17, pp. 1-37.

[13] Lin, H., 2008, Quality Choice and Market Structure: A Dynamic Analysis of Nursing Home Oligopolies. Manuscript. Indiana University. Business School. 
[14] Toivanen, O., and M. Waterson. 2005 "Market Structure and Entry: Where's the Beef?," RAND Journal of Economics, 36(3), 680-699.

[15] Ingo Vogelsang and Bridger Mitchell. 1997 "Telecommunications Competition : The Last Ten Miles," AEI Press 
Figure 1: Share of Dominant Carrier in Building FTTH Line
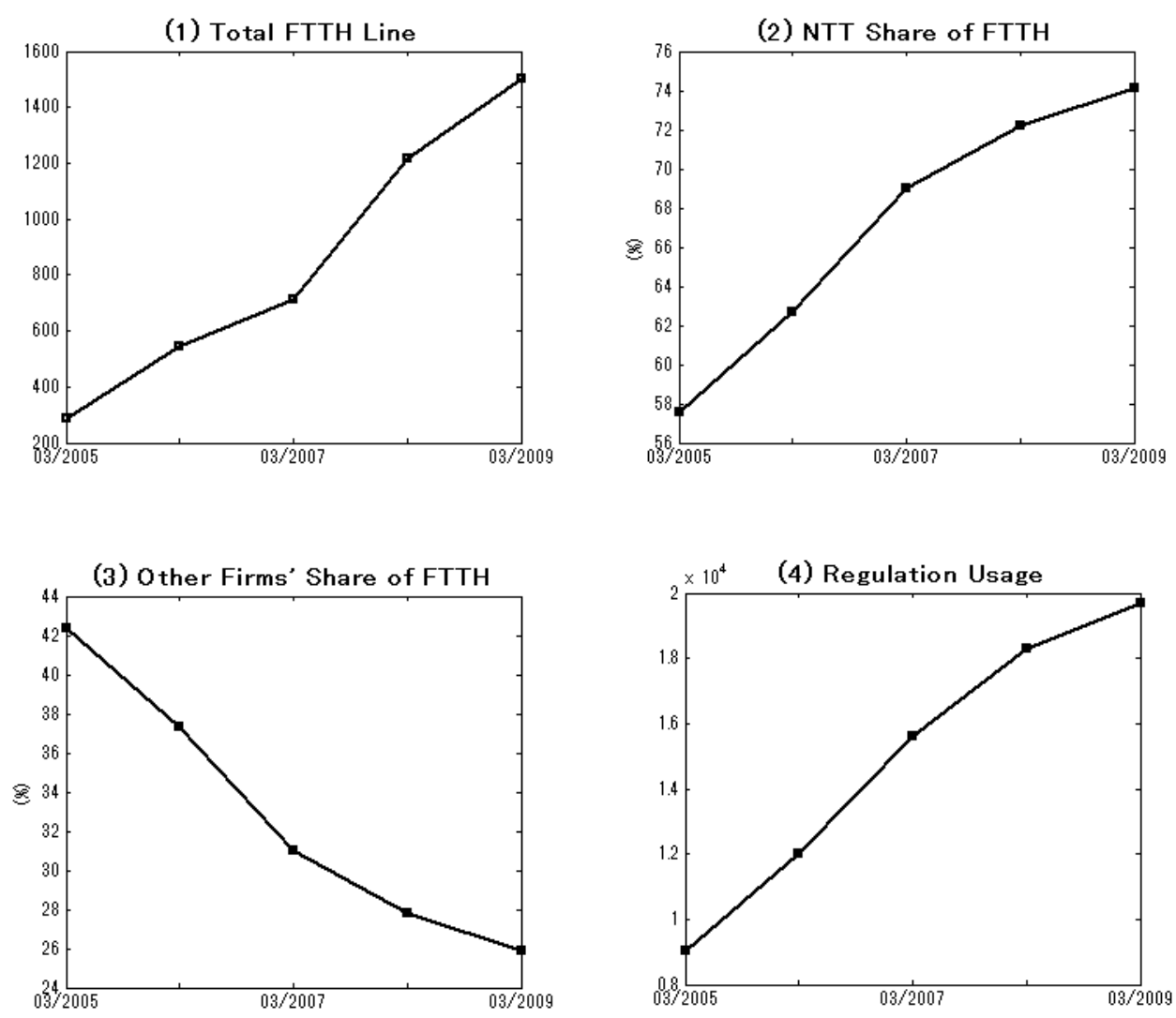

Table 1: Regulation on the Telecommunication Industry

\begin{tabular}{cccccc}
\hline \hline & US & Japan & Germany & France & UK \\
\hline Metallic Line & $\mathrm{R}$ & $\mathrm{R}$ & $\mathrm{R}$ & $\mathrm{R}$ & $\mathrm{R}$ \\
Fiber-optic Line & $\mathrm{U}^{* 1}$ & $\mathrm{R}$ & - & - & - \\
\hline
\end{tabular}

"R" means Regulated, "U" means Unregulated.

*1 The US abolished the regulation to induce investment in 2003

Table 2 :Share of FTTH in June 2009 (Top 5 Countries)

\begin{tabular}{cccccc}
\hline \hline & US & Japan & Germany & France & UK \\
\hline \# of Broadband Subscriber & 81.2 & 30.9 & 24.1 & 18.6 & 17.7 \\
Fiber-optic Share & $6 \%$ & $51 \%$ & $0 \%$ & $0 \%$ & $0 \%$ \\
\hline
\end{tabular}

Broadband subscriber is in millions. Source: OECD 
Figure 2: Industry Structure

The Case of High Speed Internet in Tokyo in June 2010

Internet Providers without Facility

525 Yen - 1890 Yen

More than 200 firms
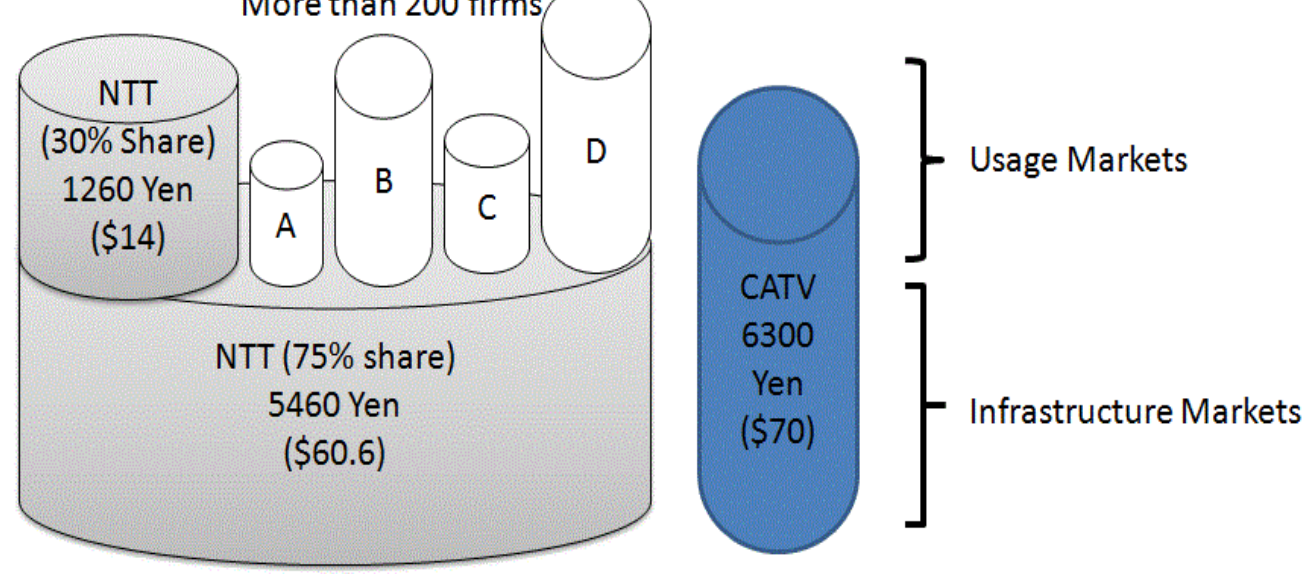

Total 6720 Yen $(\$ 74.6)$

$200 \mathrm{Mbps}$

Total 6300 Yen $(\$ 70.0)$

$160 \mathrm{Mbps}$

Table 3: Number of CATV firms that operates FTTH (Firm Level)

\begin{tabular}{llllll}
\hline & 2005 & 2006 & 2007 & 2008 & 2009 \\
\hline Total Number & 12 & 28 & 29 & 40 & 42 \\
Enter & - & 16 & 1 & 12 & 4 \\
Exit & - & 0 & 0 & 1 & 2 \\
\hline
\end{tabular}

Table 4:Number of CATV Firms (Market Level)

\begin{tabular}{lllllllllll}
\hline \hline & \multicolumn{3}{c}{2005} & \multicolumn{2}{c}{2006} & \multicolumn{2}{c}{2007} & \multicolumn{2}{c}{2008} & \multicolumn{2}{c}{2009} \\
\# Firms & CATV & FTTH & CATV & FTTH & CATV & FTTH & CATV & FTTH & CATV & FTTH \\
\hline 0 & 542 & 912 & 591 & 858 & 578 & 852 & 572 & 792 & 542 & 772 \\
1 & 300 & 50 & 272 & 94 & 276 & 99 & 283 & 147 & 299 & 164 \\
2 & 94 & 0 & 75 & 10 & 85 & 11 & 84 & 21 & 95 & 24 \\
3 & 21 & 0 & 18 & 0 & 17 & 0 & 17 & 2 & 19 & 2 \\
4 & 4 & 0 & 5 & 0 & 4 & 0 & 5 & 0 & 6 & 0 \\
5 & 1 & 0 & 1 & 0 & 2 & 0 & 1 & 0 & 1 & 0 \\
$>5$ & 0 & 0 & 0 & 0 & 0 & 0 & 0 & 0 & 0 & 0 \\
\hline Max & 5 & 1 & 5 & 2 & 5 & 2 & 5 & 3 & 5 & 3 \\
\hline
\end{tabular}


Figure 3: Market Definition: Eastern Japan

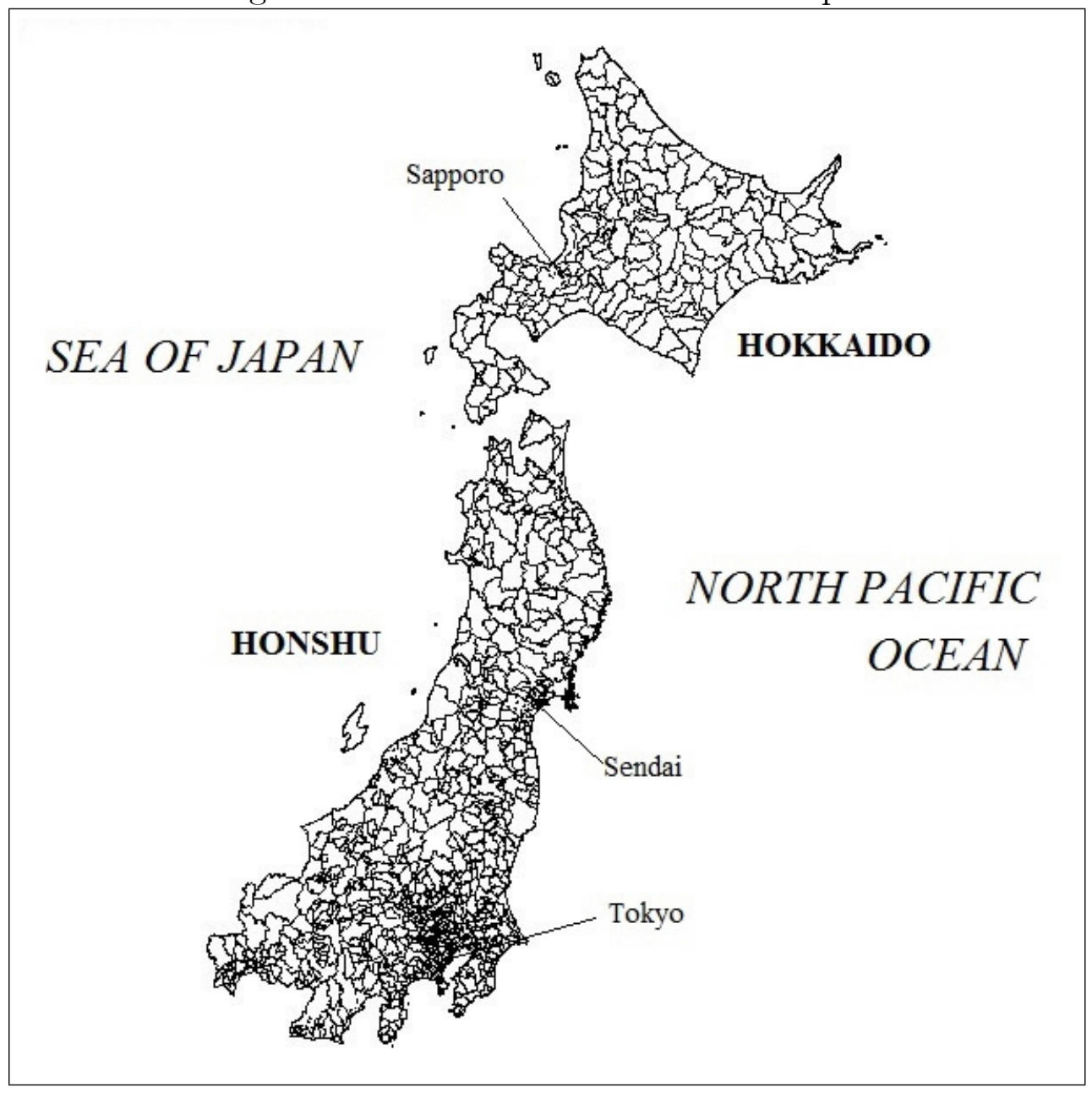

Table 5: Number of Stations of NTT

\begin{tabular}{llllll}
\hline \hline & 2005 & 2006 & 2007 & 2008 & 2009 \\
\hline Number & 3261 & 3414 & 3527 & 3691 & 3762 \\
\hline
\end{tabular}


Table 6: Summary Statistics (962 markets, 5 years)

\begin{tabular}{lllll}
\hline \hline & Mean & Std & Min & Max \\
\hline \# of families & 25924 & 44280 & 131 & 40910 \\
\# of firms that uses NTT's facilities (home to station) & 5.05 & 6.09 & 0 & 69 \\
\# of firms that uses NTT's facilities (station to station) & 6.41 & 6.70 & 0 & 74 \\
\# of station & 3.67 & 3.66 & 0 & 22 \\
usage per household of home to station & .0005 & .0008 & 0 & .140 \\
usage per household of station to station & .0007 & .0010 & 0 & .140 \\
\# of CATV firms & .56 & .79 & 0 & 5 \\
\# of FTTH entry of CATV firms & .15 & .39 & 0 & 3 \\
Entry rate in FTTH by CATV firms & .26 & .40 & 0 & 1 \\
\hline
\end{tabular}

Table 7: Market Characteristics

\begin{tabular}{llllll}
\hline \hline $\begin{array}{l}\text { \# of fiber } \\
\text { CATV }\end{array}$ & \# of households & station to home & station to station & \# of CATVs & \# of stations \\
\hline 0 & 19402 & 3.9 & 5.3 & 0.4 & 3.3 \\
1 & 62164 & 10.9 & 12.3 & 1.4 & 5.5 \\
2 & 126650 & 21.3 & 24.2 & 2.6 & 7.9 \\
3 & 170145 & 23.8 & 24.8 & 3.25 & 7.5 \\
\hline
\end{tabular}


Table 8: Results of Linear Regression Model

\begin{tabular}{|c|c|c|c|}
\hline & (1) GLS & (2) 2SLS & (3) Tobit \\
\hline Usage per household & $\begin{array}{c}0.00 \\
(0.01)\end{array}$ & $\begin{array}{c}0.00 \\
(0.01)\end{array}$ & $\begin{array}{c}-0.07^{* * *} \\
(0.02)\end{array}$ \\
\hline Number of NTT's & -0.01 & $-0.08^{* *}$ & $-0.11^{* * *}$ \\
\hline fiber station per density & $(0.02)$ & $(0.02)$ & $(0.05)$ \\
\hline Traffic Demand & $\begin{array}{c}-3.77^{* * * *} \\
(1.32)\end{array}$ & $\begin{array}{c}-3.79 * * * \\
(1.32)\end{array}$ & $\begin{array}{c}-17.3^{* * *} \\
(1.92)\end{array}$ \\
\hline $\begin{array}{c}\text { Number of People } \\
\text { per household }\end{array}$ & $\begin{array}{c}1.50^{* * *} \\
(0.49)\end{array}$ & $\begin{array}{c}1.51^{* * *} \\
(0.49)\end{array}$ & $\begin{array}{c}6.51^{* * * *} \\
(0.70)\end{array}$ \\
\hline Number of household & $\begin{array}{c}3.79 * * * \\
(1.33)\end{array}$ & $\begin{array}{c}3.81^{* * * *} \\
(1.33)\end{array}$ & $\begin{array}{c}17.2^{* * *} \\
(1.93)\end{array}$ \\
\hline Density & $\begin{array}{c}0.02 \\
(0.04)\end{array}$ & $\begin{array}{c}0.02 \\
(0.04)\end{array}$ & $\begin{array}{c}-0.18^{* * *} \\
(0.07)\end{array}$ \\
\hline Average Income & $\begin{array}{c}0.04 \\
(0.15)\end{array}$ & $\begin{array}{c}0.04 \\
(0.16)\end{array}$ & $\begin{array}{l}-0.32^{*} \\
(0.18)\end{array}$ \\
\hline Const & $\begin{array}{c}-5.50^{* * *} \\
(1.89)\end{array}$ & $\begin{array}{c}-5.52^{* * *} \\
(1.89)\end{array}$ & $\begin{array}{l}-24.8 \\
(2.77) \\
\end{array}$ \\
\hline Year Dummy & $\sqrt{ }$ & $\sqrt{ }$ & $\sqrt{ }$ \\
\hline Market Dummy & $\sqrt{ }$ & $\sqrt{ }$ & $\sqrt{ }$ \\
\hline Endogeneity $^{* 2}$ & - & $\sqrt{ }$ & - \\
\hline Censored $^{* 3}$ & - & - & $\sqrt{ }$ \\
\hline Adjusted $\mathrm{R}^{2}$ & 0.06 & - & - \\
\hline $\mathrm{F}$ test & - & - & - \\
\hline Wald test & 35.6 & 34.9 & 356.4 \\
\hline Log likelihood & - & - & -1620.0 \\
\hline
\end{tabular}

Note: Dependend variable is the share of CATV firms that build fiber-optic networks

*1: usage is the number of firms per household that use the regulated facility between home and station

$*_{2}$ : In the IV estimation, this paper uses the number of firms that use the regulated facility between station and station as the instrument of usage *3: In the Tobit estimation, the upper and lower bounds are 0 and 1 , each.

$*$ is significant at $10 \%,{ }^{* *}$ is at $5 \%$ and ${ }^{* * *}$ is at $1 \%$. Parenthis is standard deviation. 


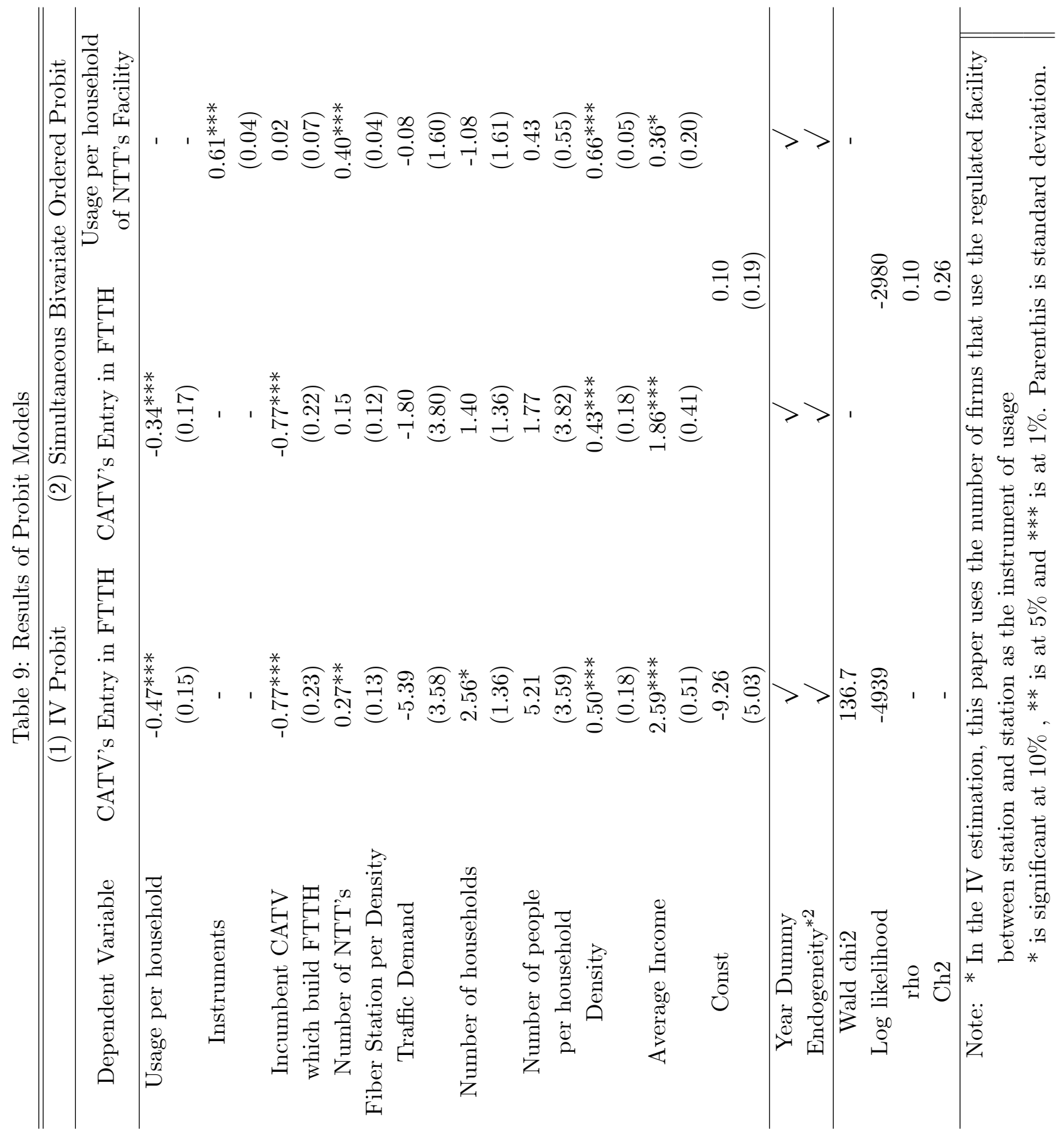




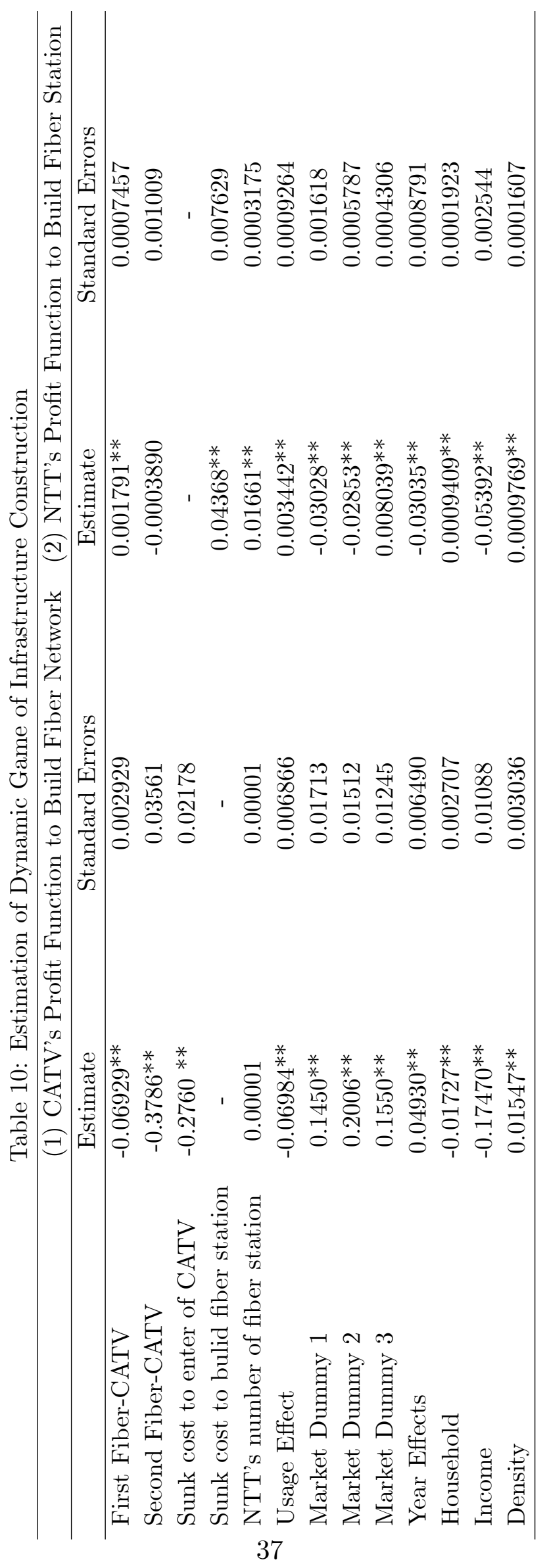

